\title{
Some attitudinal predictors of fair-trade buying behavior in the United States
}

\author{
Shawn M. Newhouse \\ Vice President for Traditional Undergraduate Academics \\ Cornerstone University \\ United States of America \\ Tom A. Buckles \\ Department of Marketing \& Entrepreneurship \\ School of Business \& Management \\ Azusa Pacific University \\ United States of America
}

\section{Key Words}

Attitudes, Buyer Behaviour, Cultural Intelligence, TORA/TOPB, Fair Trade, SEM,

\begin{abstract}
The purpose of this research was to determine which attitudes predict the propensity of individual consumers in the United States to purchase fair trade products. In doing so, drivers of fair-trade growth and implications for marketing strategy were identified.

Previous research regarding attitudes that predict fair trade consumption had been conducted primarily in Europe. In contrast, few attitudinal studies utilizing a probability sample had been conducted within the context of the United States. This effort replicated a study previously conducted in Belgium in 2007 by De Pelsmacker and Janssens utilizing their model for fair trade buying behavior, which found a connection between positive attitudes and level of fair trade knowledge, perception of fair trade information quality, degree of product interest, degree of product likeability, and price perception. Similar empirical studies conducted in the United States have been limited (particularly those involving a probability sample), providing marketers with little understanding of the American fair-trade consumer (Pharr, 2011). In addition, few studies have been replicated in multiple markets, limiting an understanding of the global fairtrade consumer.

Using an online survey facilitated by a panel provider, data was collected from consumers in the United States ages 18 and older. Structural equation modeling was employed to examine attitudes and their relationship to fair trade purchase levels. Results indicated that knowledge of fair trade, skepticism, information quality, and product likeability are important attitudes when considering fair trade buying behavior of consumers in the United States. Knowledge levels of fair trade and information about fair trade that is of high quality had a direct impact on fair trade buying behavior. While reduced levels of skepticism impacted attitudes toward fair trade products, positive attitudes toward fair trade products did not produce fair trade buying behavior.
\end{abstract}

Corresponding author: Tom A. Buckles

Email addresses for the corresponding author: tabuckles@gmail.com

First submission received: $15^{\text {th }}$ September 2018

Revised submission received: $20^{\text {th }}$ April 2020

Accepted: 25th April 2020

\section{Introduction}

Despite the growth trajectory of the market for fair trade goods in the United States, there is a limited body of research explaining why individual consumers in the United States purchase fair trade products (Andorfer \& Liebe, 2012; King, 2013). In particular, there have been few empirical studies utilizing a probability sample that focus on which consumer attitudes facilitate fair trade buyer behavior (Doran, 2009; Pharr, 2011). The purpose of this study was to determine which attitudes predict the propensity of individual consumers in the United States to buy fair trade products. By identifying these 
attitudes, marketers can better identify drivers of growth and make better strategy decisions for marketing fair trade products.

This paper is organized as follows. First, an introduction to the present research is provided, followed by a discussion of the problem and research hypotheses. An overview of the methodology and key findings are then presented, and the paper concludes with a discussion of professional significance, research limitations and suggestions for additional research.

De Pelsmacker \& Janssens (2007) developed a model for fair trade buyer behavior based on the Theory of Reasoned Action and Planned Behavior (TOPB). This model specifically explored the attitudes that impact fair trade buying behavior in Belgium and found that positive attitudes related to fair trade knowledge, fair trade information, interest in fair trade products, and general attitude toward fair trade impacts fair trade buying behavior. The current research replicated the study conducted by De Pelsmacker \& Janssens to determine attitudes that impact fair trade buying behavior in the United States. Other research that has explored fair trade buying behavior based on the TOPB has allowed for additional predictors (Shaw, Shiu, \& Clark, 2000). Given this, the current study also explored the possible link between fair trade buyer behavior and cultural intelligence.

The study conducted by De Pelsmacker \& Janssens' (2007) in Belgium and an additional study conducted by Ozcaglar-Toulouse et al.(2006) found support for hypotheses suggesting consumers who understand what fair trade is about typically have positive attitudes toward the issue and are more likely to buy fair trade products. Based on these results, research hypotheses for the current study are identified in Table 1 below.

\begin{tabular}{|l|l|}
\hline Notation & Hypothesis Statement \\
\hline $\mathrm{H}_{1 a, b, c, d}$ & $\begin{array}{l}\text { Individuals with a higher level of fair-trade knowledge will have positive attitudes regarding } \\
\text { (a) fair trade, (b) fair trade information, (c) fair trade products, and (d) will purchase more. }\end{array}$ \\
\hline $\mathrm{H}_{2 a, b}$ & $\begin{array}{l}\text { Individuals with positive attitudes towards fair trade will have (a) positive attitudes toward } \\
\text { fair trade products and will (b) purchase more. }\end{array}$ \\
\hline $\mathrm{H}_{3 a, b, c}$ & $\begin{array}{l}\text { Positive perception of fair-trade information quantity will result in positive attitudes towards } \\
\text { (a) fair trade, (b) fair trade products and (c) higher levels of buyer behavior. }\end{array}$ \\
\hline $\mathrm{H}_{4 a, b, c}$ & $\begin{array}{l}\text { Positive perception of fair-trade information quality will result in positive attitudes towards } \\
\text { (a) fair trade, (b) fair trade products and (c) a higher levels of buyer behavior. }\end{array}$ \\
\hline
\end{tabular}

Table 1: Research Hypotheses

\section{Methodology}

The research was completed using a stratified probability sample of consumers in the Unites States ages 18 and older in the year 2014. Qualtrics, Inc. administered the online survey, which included the original questionnaire developed by De Pelsmacker \& Janssens to measure knowledge, information quantity, information quality, skepticism, concern, product interest, product likability, price acceptability, and convenience. Demographic data were also collected.

The relationships between consumer attitudes toward fair trade and fair-trade buying behavior were examined utilizing structural equation modeling, including exploratory factor analysis, assessment of measurement model validity, and specification of the structural model. It was anticipated that a positive relationship between levels of fair-trade knowledge, perception of fair-trade information, general attitudes toward fair trade and attitudes toward fair trade products and levels of fair-trade buying behaviour would be identified. As such, support was expected for $\mathrm{H}_{1}, \mathrm{H}_{4}, \mathrm{H}_{5 b}, \mathrm{H}_{5 c}$, and no support was expected for $\mathrm{H}_{5 \mathrm{a}}$. Results of the study can be used by fair trade marketers to make strategy decisions that enhance attitudes that most impact levels of fair trade buying behavior.

\section{Discussion and Implications of the Research Results}

Results of the current research are discussed in this section. Additionally, the relationship of the current study to previous research is explored. The section continues with comments regarding theoretical implications, professional significance, and marketing strategy. 


\subsection{Results Interpretation}

Based on the research hypotheses, this section describes the outcomes of the study, identifying the factors that contribute to fair trade buying behavior in the United States.

$\mathrm{H}_{1}$. Individuals with a higher level of fair-trade knowledge will have positive attitudes regarding (a) fair trade, (b) fair trade information, (c) fair trade products, and (d) will purchase more.

The study supported research hypotheses $\mathrm{H}_{1 \mathrm{a}}$, a portion of $\mathrm{H}_{1 \mathrm{c}}$, and $\mathrm{H}_{1 \mathrm{~d}}$. Results indicated that consumers who know more about what fair trade is and how it benefits producers in marginalized economies are less skeptical of the ability of fair trade to achieve its goals. Additionally, consumers that know more about fair trade are more likely to have a positive perception of the quality of fair-trade products in relation to "normal" products. Lastly, consumers that know more about what fair trade is and its benefits to producers were found to buy more fair-trade products.

Contrary to the Belgian study, the results did not reveal significant support for a positive relationship between knowledge of fair trade and perception of fair-trade information quantity and fairtrade information quality. Additionally, high levels of fair-trade knowledge were not indicative of positive perceptions of fair-trade pricing levels.

$\mathrm{H}_{2}$ : Individuals with positive attitudes towards fair trade will have (a) positive attitudes toward fair trade products and (b) will purchase more.

Consumers that were less skeptical about the fair-trade issue were found to perceive fair trade products as priced at an acceptable level. This supports the idea that consumers who believe that the fairtrade process works do not mind paying more for the products. Unexpectedly, consumers with lower levels of skepticism towards fair trade were found to have a negative view of fair-trade products in terms of their quality. It was anticipated that lower levels of skepticism would result in higher levels of fairtrade product likeability.

The direct relationship between a consumer's general attitude toward fair trade and fair-trade buying behavior was not significant. Therefore, $\mathrm{H}_{2 \mathrm{~b}}$ is not supported.

$\mathrm{H}_{3}$ : Positive perception of fair-trade information quantity will result in positive attitudes towards (a) fair trade, (b) fair trade products, and (c) higher levels of buyer behavior.

The quantity of information available to consumers regarding fair trade and the fair trade behavior of companies did not impact attitudes toward fair trade and fair-trade products. Additionally, a consumer's perceived level of information quantity was not a good predictor of fair-trade buying behavior as the relationship was not significant. Therefore, $\mathrm{H}_{3 \mathrm{a}, \mathrm{b}, \mathrm{c}}$ is not supported.

$\mathrm{H}_{4}$ : Positive perception of fair-trade information quality will result in positive attitudes towards (a) fair trade, (b) fair trade products, and (c) higher levels of buyer behavior.

When the information presented regarding fair trade is perceived as professional, controllable, and credible, consumers had lower levels of skepticism toward the fair-trade issue. However, higher levels of information quality did not result in consumers perceiving fair trade products to be likeable and priced at an acceptable level. Higher levels of information quality resulted in consumers purchasing more fair-trade products. Therefore, while $\mathrm{H}_{4 \mathrm{a}}$ and $\mathrm{H}_{4 \mathrm{c}}$ are supported, $\mathrm{H}_{4 \mathrm{~b}}$ is not.

In summary, knowledge of fair trade, skepticism, information quality, and product likeability are important factors when considering fair trade buying attitudes of consumers in the United States. Knowledge levels of fair trade and information about fair trade that is of high quality have a direct relationship to fair trade buying behavior. It should be noted that the relationship between knowledge and buyer behavior is stronger than the relationship between information quality and buyer behavior. While reduced levels of skepticism impact attitudes toward fair trade products, positive attitudes toward fair trade products do not produce fair trade buying behavior. Figure 1 shows the significant paths of the estimated model for fair trade buying behavior. 


\subsection{Relationship of Current Study to Previous Research}

The findings in this study both support and negate findings from earlier empirical studies on attitudes and motivations toward fair trade products. First, earlier studies found that attitudes toward the fair-trade concept have a direct and indirect effect on buyer behavior (De Pelsmacker \& Janssens, 2007; Peregal \& Ozcaglar-Toulouse, 2001). The current study does not support the direct effect of attitudes toward the fair-trade concept and buyer behavior but does support indirect effects. The challenge in the current study is that there is not a direct path from the indirect effects to buyer behavior. Also, De Pelsmacker \& Janssens' (2007) finding that attitude toward fair trade products impacts fair trade buyer behavior directly is not supported in the current study.

Earlier studies conducted in Europe supported the premise that consumer knowledge of fair-trade impacts fair trade buying behavior (Becchetti \& Rosati, 2007; Carrigan, et al., 2007). Results of the current study aligned with the findings from these European studies.

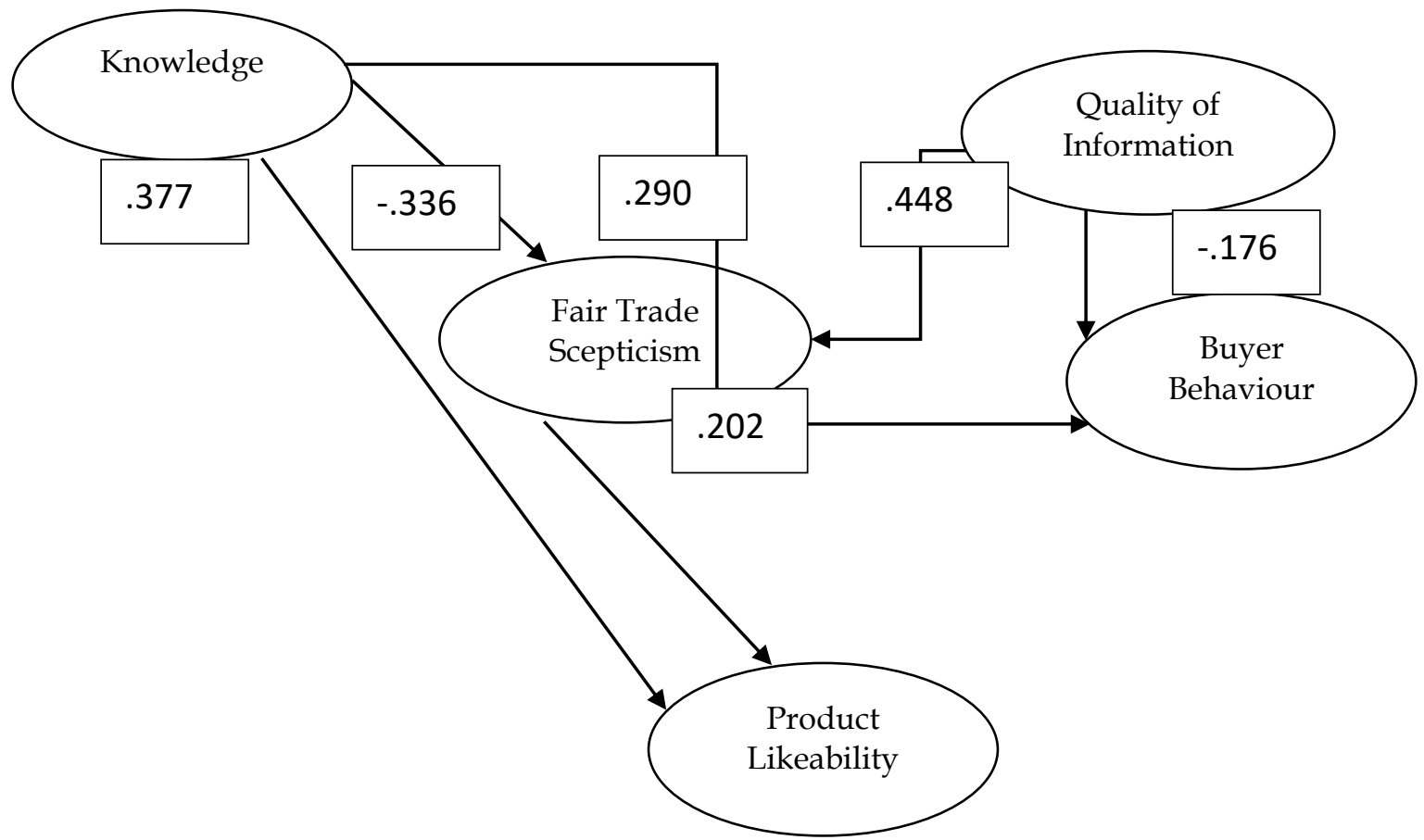

Figure 1: Estimated Model for Fair Trade Buying Behavior - Significant Paths

The current study also supported earlier findings that the quality of fair-trade information has a positive impact on fair trade buyer behavior (Carrigan, et al.,2004; d'Astous \& Mathieu, 2008; De Pelsmacker \& Janssens, 2007). In this study, the availability of high-quality fair-trade information had a direct and indirect impact on fair trade buying behavior. One difference was identified, however. In De Pelsmacker \& Janssens' 2007 study, high quality information increased the level of skepticism toward fair trade in general. Results were opposite in the current study where high-quality information resulted in reduced skepticism. Also, in the current study, a relationship between high quality information and attitudes toward fair trade products was not identified. This opposes the findings of earlier studies. Overall, the present study gives strength to findings that quality information plays an important role in fair trade buyer behavior over the long-term.

This research effort revealed the attitude/behavior gap identified in earlier studies where positive attitudes and purchase intentions for fair trade products and fair trade in general did not necessarily translate to fair trade buyer behavior (De Pelsmacker, et al., 2006; Nicholls \& Lee, 2006; Uusitalo \& Oksanen, 2004). While the current study revealed significant paths toward skepticism (reduced), price acceptability, and product likeability, results did not reveal a significant path from these attitudes to buyer behavior. One study suggested that reducing the barriers of lack of information, high price, and difficulty 
in finding the products would move consumers from purchase intention to buyer behavior (Shaw, et al., 2006). Others suggested that the gap could be filled when consumers feel they can make a difference (Carrigan, et al., 2004; Wright \& Heaton, 2006). Brand building was also identified as a way to close the gap (Nicholls \& Lee, 2006).

Concerning the model for fair trade buying behavior developed by De Pelsmacker \& Janssens (2007), fewer factors appear to impact fair trade buying behavior in the United States in comparison to Belgium. The Belgian study revealed several direct and indirect paths to buyer behavior. Three of the original factors included in the Belgian study: convenience, concern, and product interest were removed from the current model as the data did not fit the model. Convenience also did not provide adequate model fit in the Belgian study but was retained in that study for its perceived importance to the model. Additionally, in this study, information quantity did not prove to be a relevant part of the model.

While studies found that positive attitudes toward fair trade knowledge and information quality resulted in reduced skepticism, acceptance of fair trade pricing, and likeability of fair trade products, these paths did not result in the same fair trade buyer behavior as they did in the Belgian study. Only fair-trade knowledge and quality of fair-trade information directly translated to fair trade buying behavior in the United States. In the Belgian study, the relationship between knowledge and attitudes toward fair trade products was removed because it did not result in a well-fitting model. This path was modeled in the U.S. study, however, and the path proved to be important.

The differences found in the two studies are supported by the research of Adams and Raisborough (2010) that suggested the balance between consumption and ethics (i.e. fair trade) is complex and often uneven in practice. Consumers often support the fair-trade concept, but buyer behavior can be difficult given obstacles such as perception of the role of big business in the distribution chain, pricing issues, lack of ability to check fair trade claims, etc. Some of these obstacles may be overcome by marketing solutions, which will be discussed in the professional significance section.

In summary, findings of this research in relationship to prior studies affirm the impact of knowledge and quality of information on fair trade buyer behavior across markets. Additionally, the present study affirms the presence of an attitude/behavior gap where positive attitudes and purchase intentions toward fair trade and fair-trade products do not always result in fair trade buying behavior.

3.3 Theoretical Implications. Results of the current study support the role of the Theory of Reasoned Action (TORA) and the Theory of Planned Behavior (TOPB) as the foundation for the fair-trade buying behavior model. While many of the factors in De Pelsmacker \& Janssens' model for fair trade buying behavior were retained in the current study, some factors were not. As a result of cross-loading in the exploratory factor analysis (EFA), the Convenience factor (and related item) was eliminated from the model. Problems were noted in regard to the Concern factor in the EFA. One item was not significant, and another loaded low.

When examining the Concern factor in the measurement model, the decision was made to remove it as it presented several challenges in terms of cross-loadings and fit of the final item (the one item that loaded well in the EFA). The Product Interest factor was also eliminated in the measurement model as its inclusion in the model did not fit the data well. Reasons for the differences between the two models include (but are not limited to) differences in the targeted audience at a different point in time as well problems of understanding/clarity in terms of the survey questions.

As noted in Table 2 below, while the Fair-Trade Information Quantity and Fair-Trade Information Quality constructs were retained in the U.S. model, Fair Trade Information Quantity did not play a significant role in the U.S. market in terms of fair-trade buying behavior. Knowledge, Skepticism, Price Acceptability, and Product Likeability were retained in both models. Buyer Behavior was also retained in both models, with the inclusion of an additional item in the U.S. model.

While the overarching dimensions of De Pelsmacker and Janssens' model of fair trade buying behavior (Knowledge, Information About Fair Trade, General Attitude Towards Fair Trade, Attitude Towards Fair Trade Products, and Fair Trade Buying Behavior) seem to be relevant across markets, the individual factors associated with each dimension may not be relevant in every market. As this model is 
utilized in other markets, researchers should expect all dimensions of the model to be present, but individual factors should be tested for validity.

\begin{tabular}{|l|l|l|l|}
\hline \multirow{2}{*}{ Dimension } & Factor & Belgian Model & U.S. Model \\
\hline Knowledge & Knowledge & Included, Relevant & Included, Relevant \\
\hline $\begin{array}{l}\text { Information About Fair } \\
\text { trade }\end{array}$ & Information Quantity & Included, Relevant & Included, Not Relevant \\
\cline { 2 - 4 } $\begin{array}{l}\text { General Attitude } \\
\text { Towards Fair Trade }\end{array}$ & Information Quality & Included, Relevant & Included, Relevant \\
\hline \multirow{3}{*}{$\begin{array}{l}\text { Attitude Towards Fair } \\
\text { Trade Products }\end{array}$} & Soncern & Included, Relevant & Not Included \\
\cline { 2 - 4 } & Price Acceptability & Included, Relevant & Included, Relevant \\
\cline { 2 - 4 } & Product Likeability & Included, Relevant & Included, Relevant \\
\cline { 2 - 4 } & Product Interest & Included, Relevant & Included, Relevant \\
\cline { 2 - 4 } & Convenience & Included, Not Relevant & Not Included \\
\hline Buyer Behavior & Buyer Behavior & Included, Relevant & Included, Relevant \\
\hline
\end{tabular}

Table 2. A Comparison of De Pelsmacker and Janssens' Model for Fair Trade Buying Behavior: Belgium vs. United States

\subsection{Professional Significance}

Results of this study offer many insights to marketers of fair-trade products and researchers that study fair trade buyer behavior. First, greater understanding of consumer attitudes that impact fair trade buyer behavior in the United States has been achieved. The ability of consumers to accurately define fair trade as well as the perceived degree of quality of information available to them had a direct impact on the number of fair-trade products that they purchase. Reduced levels of skepticism toward the fair-trade concept (belief that it can work) were found to create positive attitudes towards pricing levels and product quality. However, they did not translate to increased levels of buyer behavior. Knowledge and quality information also reduced consumer skepticism.

This study also presented an opportunity to generalize findings across markets. As discussed earlier, the role of knowledge and quality of information were important this study as well as in prior studies conducted in Europe. Given this, from a global perspective, consumers that have the information and ability to accurately define fair trade and have access to fair trade information that is professional, controllable, and credible are more likely to purchase fair trade products. Additionally, across markets there is evidence of an attitude/behavioral gap. In other words, consumers may have positive attitudes toward fair trade in general and fair-trade products but may not buy them.

This leads to the next point in terms of suggestions for drivers of growth for fair trade in the United States. Marketers in the United States should work to close the gap between attitudes \& buyer behavior to stimulate market growth. Based on prior research, these barriers can be overcome by consumers feeling like they can actually make a difference in the lives of producers from developing economies. Also, brand building (awareness and image) was identified as a way to close the gap.

Given the direct link between knowledge of fair trade and buying behavior, marketers of fair trade should work to increase knowledge levels of fair trade across the United States. While the U.S. market for fair trade product is growing, it is still rather small (approximately \$2 billion USD) (King, 2013; Satran,2012). Perhaps if more understood fair trade and what it can do for producers in developing economies, more consumers will buy the products. Various regions of the country that have lower knowledge levels could be exposed to selective high-quality fair-trade information.

As marketers work to create awareness of what fair trade is, they should seek to do so in a manner that is professional, controllable, and credible. Given that quantity of information was not relevant in this study, marketers should continue to choose quality over quantity. As stated by De Pelsmacker and Janssens (2007), consumers that perceive that the quality of information is high are more likely to perceive that there is a sufficient amount of it. 


\subsection{Marketing Strategy}

Keeping in mind the drivers of growth in the United States, marketers should make adjustments to fair trade marketing strategies. In terms of product strategy, marketers of fair-trade products should continue to make sure that the products are of high quality. Consumers are asked to pay a higher price for fair trade products, so product expectations (in terms of taste, health, and quality) should be met. It is not enough only to satisfy altruistic needs. Also, in an effort to close the attitude/behavior gap, fair trade marketers should work to build their brands. Part of this strategy should involve creating an understanding of fair trade (knowledge) and providing information about the brand/product that is of high quality. When choosing a branding strategy, marketers should be aware that niche consumers are often wary of branding strategies that look and feel like big company branding. Efforts should be made to choose branding strategies that appeal to the niche, i.e. making a connection to fair trade principles and certification as well as providing evidence that consumers can (and do) make a difference.

Fair trade brands should continue to select their channels of distribution carefully. While fair trade products are becoming more widely distributed in the United States, marketers should select channels whose practices align with fair trade principles. For example, consumers tend to be wary of Walmart's practice of demanding low wholesale prices often at the expense of members of the distribution chain. In this regard, Walmart's reputation may be a stumbling block for a fair-trade brand looking to expand its reach from a distribution standpoint.

Pricing strategy will continue to be important for marketers of fair-trade products. Consumers that accurately understand the fair-trade concept are generally less skeptical and accepting of higher prices that accompany fair trade products. Studies have been conducted across several markets to consider how much consumers are willing to pay for fair trade products. Given the results of the current study, marketers that work to help consumers accurately understand fair trade by providing information that is of high quality will encounter less price resistance in the marketplace. In general, positive attitudes towards fair trade translate to a willingness to pay more for fair trade products (Arnot, et al., 2006; Becchetti \& Rosati, 2007; Hustvedt \& Bernard, 2010; Yang, et al., 2013). However, pricing will continue to be an issue when marketing fair trade products in the United States and marketers will need to work to find a balance between profitability and affordability. The current study also revealed a gap between positive attitudes towards the price of fair-trade products and the act of actually purchasing fair trade products. As noted in the product strategy section, marketers should continue to work on brand building and reinforcement of the message that buying fair trade makes a difference for marginalized producers in developing economies in an effort to close the gap.

From a promotional strategy perspective, marketers should focus on creating awareness among consumers (current \& prospective) in terms of the tenets of fair trade. This should be done in a manner that projects professionalism and credibility. Also, special care should be taken to carefully target consumers versus a mass marketing approach. Messages should be consistent and should demonstrate that fair trade works and makes a difference in the lives of producers around the globe. Social media strategies should be considered as word of mouth promotion and have been deemed an important promotional strategy for fair trade products (Wright \& Heaton, 2006). Additionally, product labels and point of purchase materials should be of high quality and should be utilized to convey fair trade knowledge, information, and certification. Increased opportunities for in-store product trial should be considered in an effort to strengthen product likeability attitudes in an effort to stimulate buyer behavior.

Finally, this study also strengthens the theoretical base for similar studies. As discussed in an earlier section, the current study supports the role of the Theory of Reasoned Action (TORA) and the Theory of Planned Behavior (TOPB) as the foundational theories for the fair-trade buying behavior model. Also, as a conceptual model, the study supports the main dimensions of the fair-trade buying behavior model: Knowledge, Information About Fair Trade, General Attitude Towards Fair Trade, Attitude Towards Fair Trade Products, and Buying Behavior. As discussed previously, the factors of main dimension should be tested for validity before testing the model in other countries. 


\section{Research Limitations}

The study presented limitations in terms of De Pelsmacker \& Janssens' survey. In an effort to account for translation difficulties, a pre-test was conducted. Minor changes were made to the instrument based on the results of the pretest to improve clarity. However, it is anticipated that there were still some translation issues that may have led the sample to respond in a manner that was contrary to what was expected (misunderstood the question). Efforts to translate the original Dutch/French survey to English or implementation of a full pilot study may have been more beneficial in terms of maintaining original question intent/understanding.

A second limitation of the study relates to the sample. In the original Belgian study, 615 individuals responded to the survey. This is substantially more than the 250 responses obtained for the current study. Perhaps a larger sample would provide a greater cross section of U.S. consumers. Also, the stratification process placed controls on the probable nature of the sample.

\section{Suggestions for Additional Research}

In an effort to strengthen the findings of this study, future research could include retesting De Pelsmacker \& Janssens' fair trade buying behavior model with a second sample from the U.S. excluding the cultural intelligence factors. The cultural intelligence items included the largest standardized residuals, which caused issues in terms of model fit. Also, as noted, there was a clerical error with one of the price acceptances items. A second look at the fair-trade buying behavior model would include the corrected price item. Perhaps this would make a difference in terms of closing the attitude/behavior gap between price acceptability and buying behavior. Additionally, it is recognized that there may be issues related to translation. The items in De Pelsmacker and Janssens' model could be obtained in the original languages. These items could then be translated into English again to check for translation accuracy.

Also, findings regarding which attitudes impact fair trade buying behavior (including cultural intelligence) could continue to be generalized if the model for fair trade buying behavior were tested in other developed economies. An Asian economy would be of particular interest and give insight into the transferability of attitudes that impact fair trade buying behavior between the East and West. In terms of the U.S. market, findings might be strengthened by comparing results from samples from a variety of geographical areas. For example, do the attitudes of consumers on the West Coast impact fair trade buying behavior in the same manner as attitudes of consumers in the Mid-West? If so, is the strength of the relationships similar or different?

This study also identified the attitude/behavior gap that often accompanies fair trade purchase decisions. Additional research is needed to determine why consumers do not purchase fair trade products in the United States and what activities may help to close the attitude/behavior gap.

\section{Summary}

This research adds to the body of empirical literature on fair trade buying behavior by identifying predictors of fair-trade buying behavior in the United States. A consumer's ability accurately to define fair trade and the degree of quality of information available about fair trade had a direct impact on fair trade buying behavior. Positive attitudes toward knowledge and information quality also reduced levels of consumer skepticism in terms of their perception of the ability of the fair-trade system to work. Increased levels of knowledge and reduced levels of skepticism created positive attitudes toward price acceptability and product likeability. Acceptance of fair-trade pricing and likeability of fair-trade products did not translate to fair trade buying behavior, however.

Finally, this study

- Adds to the generalizability of the findings from many attitudinal studies conducted in Europe.

- Demonstrates the degree of quality information available about fair trade impacts the number of fair-trade products that consumers purchase.

- Helps fair trade marketers eliminate the gap between positive attitudes and buyer behavior regarding fair trade products.

- Signals that positive attitudes may translate to buyer intention, but not buyer behavior. 


\section{References}

Adams, M., \& Raisborough, J. (2010). Making a difference: ethical consumption and the everyday. The British Journal of Sociology, 61(2), 256-274.

Andorfer, V. A., \& Liebe, U. (2012). Research on fair trade consumption - A review. Journal of Business Ethics, 106, 415435.

De Pelsmacker, P., \& Janssens, W. (2007). A model for fair trade buying behavior: The role of perceived quantiy and quality of information and of product-specific attitudes. Journal of Business Ethics, 75, 361-380.

Arnot, C., Boxall, P. C., \& Cash, S. B. (2006). Do ethical consumers care about price? A revealed preference analysis of fair trade coffee purchases. Canadian Journal of Agricultural Economics, 54, 555-565.

Becchetti, L., \& Rosati, F. C. (2007). Global social preferences and the demand for socially responsible products: Empirical evidence from a pilot study on Fair Trade consumers. The World Economy, 807-836.

Carrigan, M., Szmigin, I., \& Wright, J. (2004). Shopping for a better world? An interpretive study of he potential for ethical consumption within the older market. Journal of Consumer Marketing, 21(6), 401-417.

d'Astous, A., \& Mathieu, S. (2008). Inciting consumers to buy fairly-traded products: a field experiment. Journal of Consumer Marketing, 25(3), 149-157.

Doran, C. J. (2009, February). The role of personal values in fair trade consumption. Journal of Business Ethics, 84(4), 549-563.

Hustvedt, G., \& Bernard, J. C. (2010). Effects of social responsibility labelling and brand on willingness to pay for apparel. International Journal of Consumer Studies, 34, 619-626.

King, B. (2013, January 3). Market for Ethical Products Grows by Nearly \$20 Billion Despite Economic Downturn. Retrieved February 15, 2013, from Sustainable Brands:

Nicholls, A., \& Lee, N. (2006, December). Purchase decsion-making in fair trade and the ethical purchase 'gap': 'is there a fair trade twix?'. Journal of Strategic Marketing, 14, 369-386.

Ozcaglar-Toulouse, N., Shiu, E., \& Shaw, D. (2006, September). In search of fair trade: ethical consumer decision making in France. International Journal of Consumer Studies, 30(5), 502-514.

Peregal, V. D., \& Ozcaglar-Toulouse, N. (2011). Why does not everybody purchase fair trade products? The question of the fairness of fair trade products' consumption for consumers. International Journal of Consumer Studies, 35, $655-660$.

Pharr, J. M. (2011, December). At the intersection of politics and consumption: A research agenda for investigating the effects of fair trade marketing claims on ethical shopping behavior. Journal of Leadership, Accountability, and Ethics, 8(5), 63-71.

Satran, J. (2012, March 12). Fair Trade Products, Led by Ice Cream, See 75 Percent Sales Growth. Retrieved February 3, 2014, from Huffington Post: http://www.huffingtonpost.com/2012/03/14/fair-trade_n_1339288.html

Shaw, D., Hogg, G., Wilson, E., Shui, E., \& Hassan, L. (2006, December). Fashion victim: the impact of fair trade concerns on clothing choice. Journal of Strategic Management, 14, 427-440.

Shaw, D., Shiu, E., \& Clark, I. (2000). The contribution of ethical obligation and self-identity to the Theory of Planned Behavior: An exploration of ethical consumers. Journal of Marketing Management, 16, 879-894.

Uusitalo, O., \& Oksanen, R. (2004). Ethical consumerism: A view from Finland. International Journal of Consumer Studies, 28(3), 214-221.

Wright, L. T., \& Heaton, S. (2006, December). Fair Trade marketing: an exploration through qualitative research. Journal of Strategic Marketing, 14, 411-426.

Yang, S.-H., Qing, P., Hu, W., \& Liu, Y. (2013). Using a modified payment card survey to measure Chinese consumers' willingness to pay for fair trade coffee: Considering starting points. Canadian Journal of Agricultural Economics, 61, 119-139. 